\title{
РОЛЬ ЕСТЕСТВЕННОЙ ГЕНЕТИЧЕСКОЙ ИЗМЕНЧИВОСТИ В ПОВЫШЕННОЙ ЗАБОЛЕВАЕМОСТИ РАКА МОЛОЧНОЙ ЖЕЛЕЗЫ И ЯИЧНИКОВ ${ }^{1}$
}

\section{THE ROLE OF NATURAL GENETIC VARIATION IN THE INCREASED INCIDENCE OF BREAST AND OVARIAN CANCER}

\section{Z. Bisultanova \\ P. Dzhambetova M. Atsayeva \\ L. Dzhambetova}

Summary: A case-control study was conducted in 238 patients with diagnosed breast and ovarian cancer and in the control group $(n=405)$ to assess the frequency of polymorphisms of the CYP1A1 (Ile462Val, Mspl) and CYP1B1 (Val432Leu) genes and their role in the risk of developing tumors in the territory of the CR with a high level of ZNO. A comparative analysis of the frequency of minor alleles of the polymorphic variant of the CYP1A1A4889G gene in the Kursk region, which has the highest level of cancer incidence in Russia, and the results obtained in this study show a significantly significant difference in the frequency of homozygous minor $\mathrm{g}$ allele in the studied regions.

Keywords: gene polymorphism, CYP1A1 (Ile462Val, Mspl), CYP1B1 (Val432Leu), Chechen population.
Бисултанова Зура Исановна

Преподаватель, ФБГОУВО «Чеченский государственный университет», Грозный zura_sun@mail.ru

Джамбетова Петимат Махмудовна д.б.н., профессор, ФБГОУ ВО «Чеченский государственный университет», Грозный petimat-lg@rambler.ru

Ацаева Марет Махмудовна к.б.н., дочент, ФБГОУ ВО «Чеченский государственный университет», Грозный acaeva-mm@mail.ru

Джамбетова Лидия Махмудовна

Преподаватель, ФБГОУ ВО «Чеченский государственный университет», Грозный

I_dzham17@mail.ru

Аннотация: Проведено исследование типа «случай-контроль» у 238 пациентов с диагностированным раком молочной железы (РМЖ) и яичников (РЯ) и в группе контроля $(\mathrm{n}=405)$ для оценки частоты полиморфизмов генов СРР1A1 (lle462Val, Mspl) и CYP1B1 (Val432Leu) и их роли в риске развития опухолей на территории ЧР, отличающейся высоким уровнем 3Н0. Сравнительный анализ частоты минорных аллелей полиморфного варианта гена СYP1A1A4889G в Курской области, отличающейся самым высоким по России уровнем онкозаболеваемости и результатами, полученными в настоящем исследовании, показывает достоверно значимую разницу в изученных регионах по частоте гомозиготного по минорному аллелю $\mathrm{G}$.

Ключевые слова: полиморфизм генов, CYP1A1 (lle462Val, Mspl), CYP1B1 (Val432Leu), чеченская популяция.

в 2018 году» Московского научно-исследовательского онкологического института имени Герцена, следует, что в России лидером по числу заболевших оказалась Курская область: в регионе в 2018 году на 100 тысяч человек пришлось 3331,1 случая онкологических заболеваний.

Подобная дифференциация объясняется различиями в факторах среды обитания, образе жизни, типе питания, вредными привычками и, в большей степени, генетическими различиями, определяемыми полиморфными вариантами генов, по которым шел отбор в течение поколений, особенно при схожести предыдущих. Последнее утверждение находит подтверждении в открытии, которое сделали ученые из Америки и России:

Работа выполнена при поддержке гранта 18-415-200001 р_а РФФИ. 
они нашли генные мутации, позволяющие коренным народам Сибири адаптироваться к холодному климату [10]. Следовательно, исследование генетической обусловленности онкологической заболеваемости с учетом территориальных особенностей региона имеет немаловажное значение, так как оно позволяет в определённой степени оценить генетические факторы и способствовать разработке профилактических мер для снижения уровня распространённости онкопатологии среди населения.

В связи с вышесказанным нами было исследовано генетическое своеобразие цитохромов населения территорий Чеченской Республики (ЧР) с высокой частотой встречаемости онкологических заболеваний.

\section{Материал и методы исследования}

В исследовании приняли участие пациенты с онкологическими заболеваниями (рак молочной железы, рак яичников) ( $n=238)$, находящиеся на лечении в ГБУ «Республиканский онкологический диспансер» и/или находящихся на учете по месту проживания. В контрольную группу входили здоровые индивиды без наличия опухолевых образований на момент забора биологического материала и без семейной истории образования раковых опухолей ( $\mathrm{n}=405)$. Всеми участниками исследования были заполнены анкеты и информированное согласие.

Для молекулярно-генетического анализа в рамках настоящей работы были взяты образцы венозной крови. Сбор биологического материала производился в период с 2017 по 2019 гг.

\section{Методы исследования}

Для генотипирования нами были отобраны SNP, частота встречаемости которых, по мировым базам данных, не менее 5\% (dbSNP (https://www.ncbi.nlm.nih.gov/ SNP/snp_summary.cgi), International Hap Map Project (https://www.genome.gov > international-hapmap)).

Экстракцию ДНК из биологического материала проводили в соответствии с инструкцией производителя ООО «Изоген», г. Москва с помощью набора готовых реагентов DiatomDNA ${ }^{\mathrm{TM}}$ Prep200.

В настоящем исследовании применяли тетрапраймерную ПЦР, основанную на использовании двух пар праймеров, специфичных к нуклеотидным заменам. Синтез праймеров производился компанией ООО Синтол (https://www.syntol.ru) и ЗАО Евроген (http://evrogen. $\mathrm{ru} /)$.

В исследование вошли три SNP, расположенных в генах CYP1A1, CYP1B1. Выбор генов и SNP был основан на литературных данных, показывающих достоверные корреляции SNP с повышенным риском развития онкологических заболеваний.

Полученные в результате амплификации фрагменты ДНК подвергались электрофорезу в агарозном геле с добавлением бромида этидия.

Визуализация ампликонов проводилась в проходящем ультрафиолетовом свете с помощью трансиллюминатора (рисунок 1 а и 1 б).

Статистическую обработку результатов проводили с

Таблица 1.

Последовательности праймеров для генотипирования аллельных вариантов полиморфизмов генов CYP1A1 (606G> T, A4889G) иCYP1B1 (V432L 1294G>C)

\begin{tabular}{|c|c|c|c|c|}
\hline Gggagatggatggttcctaccac & \multirow[t]{4}{*}{2606345} & \multirow{4}{*}{$\begin{array}{c}\text { CYP1A1 } \\
606 \mathrm{G}>\mathrm{T} \text { AA/AC/ } \\
\complement(=0,2 / 0,7 / 0,1\end{array}$} & $\mathrm{F}$ & 388 \\
\hline cctcctaagggtggcttgtcagt & & & $\mathrm{R}$ & \\
\hline cctgcagttggcaatctgtcac & & & $F(c)$ & 155 \\
\hline cetttgctgggagacaatcaggt & & & $R(a)$ & 277 \\
\hline gagctccactcacttgacacttct & \multirow[t]{4}{*}{1048943} & \multirow[t]{4}{*}{ CYP1A1 } & $\mathrm{F}$ & 462 \\
\hline cagtgtctatgagttcaggctgaatctt & & & $\mathrm{R}$ & \\
\hline gaagtgtatcggtgagacca & & & $\mathrm{Fw}$ & 285 \\
\hline ctcccagcgggcaac & & & $\mathrm{Rm}$ & 211 \\
\hline agggaccgtctgccttgtat & \multirow[t]{4}{*}{1056836} & \multirow{4}{*}{$\begin{array}{c}\text { CYP1B1 } \\
\text { V432L } 1294 G>C\end{array}$} & $\mathrm{~F}$ & 283 \\
\hline ctctgctggtcaggtccttg & & & $\mathrm{R}$ & \\
\hline ggtctgtgaatcatgacccac & & & $F(c)$ & 105 \\
\hline cgggttaggccacttcac & & & $\mathrm{R}(\mathrm{g})$ & 216 \\
\hline
\end{tabular}



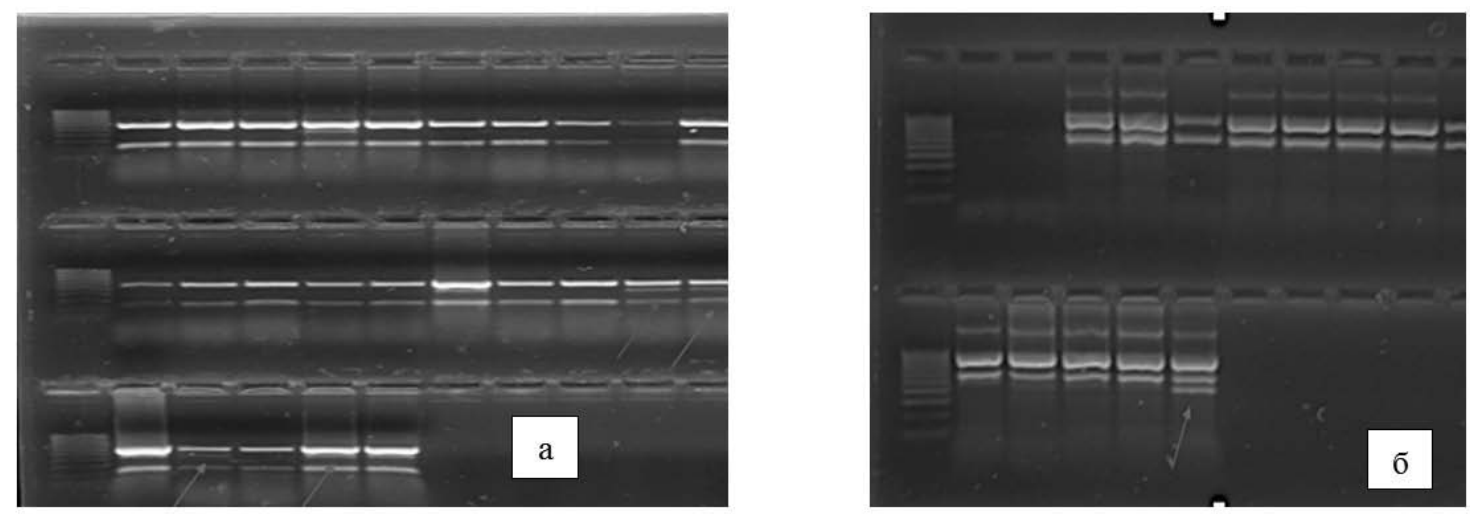

Рис. 1. Электрофореграмма результатов генотипирования аллелей полиморфизма гена а) CYP1B1V432L и б) CYP1A1 I462V. (Стрелкой показан гетерозиготный вариант генотипа).

Таблица 2.

Частота генотипов и аллелей полиморфного варианта Mspl гена CYP1A1 лиц изучаемых групп.

\begin{tabular}{|c|c|c|c|c|c|}
\hline \multirow{3}{*}{ Генотипы } & \multicolumn{2}{|c|}{ Случай n=203 } & \multicolumn{2}{|c|}{ Контроль $\mathrm{n}=402$} & \multirow{3}{*}{$p$} \\
\hline & \multicolumn{2}{|c|}{ Частота } & \multicolumn{2}{|c|}{ Частота } & \\
\hline & Aбc. & $\%$ & A6c. & $\%$ & \\
\hline TT & 84 & 41,58 & 131 & 32,6 & $\geq 0,05$ \\
\hline TC & 83 & 41,09 & 183 & 45,5 & $\geq 0,05$ \\
\hline $\mathrm{CC}$ & 36 & 17,33 & 88 & 21,9 & $\leq 0,05$ \\
\hline $\mathrm{T}$ & 251 & 61,8 & 445 & 55,3 & $\geq 0,05$ \\
\hline$C$ & 155 & 38,2 & 359 & 44,6 & $\geq 0,05$ \\
\hline HW & 0,113 & & 0,057 & & \\
\hline
\end{tabular}

помощью программы Statistica 6.0, интегрированной в Excell. Для выявления корреляций аллелей полиморфных вариантов генов с риском развития заболеваний использовали компьютерную программу WINPEPI, находящуюся в открытом доступе [7].

Результаты и обсуждение. Фермент СYР1А1 человека является наиболее активным среди СҮР в метаболизме проканцерогенов, в частности полициклических ароматических углеводородов, способствующих канцерогенезу. Нами были изучены два функциональных полиморфизма в гене CYP1A1: замена тимина (Т) на цитозин (C) в некодирующей 3'-фланкирующей области (Mspl, rs4646903) и транзиция аденин (A) на гуанин (G) в кодоне 462 в 7-м экзоне (lle462Val, rs1048943). Эти варианты могут изменять экспрессию и функцию СРР1A1, потенциально влияя на баланс между метаболической активацией и детоксикацией токсикантов, и, в конечном итоге приводят к индивидуальной восприимчивости к раку [8].

Нами был проведен анализ распространенности указанных вариантов генов CYP1B1 и CYP1A1 в когорте чеченцев, проживающих в Грозненском районе Чеченской республики, в которой отмечается наиболее высокий уровень онкозаболеваний, а также проведен сравни- тельный анализ полученных данных с данными по частоте наиболее распространенного в Курской области полиморфного варианта гена CYP1A1(Ile462Val, rs1048943), взятых из открытых источников литературы.

В таблице 2 показаны результаты генотипирования аллельных вариантов полиморфизма Mspl гена CYP1A1 в Грозненском районе ЧР.

Анализ частоты генотипов полиморфного варианта Mspl гена CYP1A1 показывает, что частота гомозиготных по минорному аллелю генотипов в районе достигает средних величин и составляет в группе больных 17,33\%, в то же время в группе контроля наблюдается увеличение доли гомозигот по сравнению с частотой аналогичного генотипа в выборке больных лиц до 21,9\% (рис. 2). Вероятно, изменение функций фермента вследствие однонуклеотидной замены и нарушение метаболизма определенной группы ксенобиотиков здесь играет защитную роль, предотвращая образование раковых опухолей. В пользу этой гипотезы говорит и тот факт, что частота носителей минорного аллеля также выше в популяционной выборке, по сравнению с показателями, полученными в выборке больных: 45,5\% против 41,9\%. При этом нами отмечалось, что индивидов с гомозигот- 


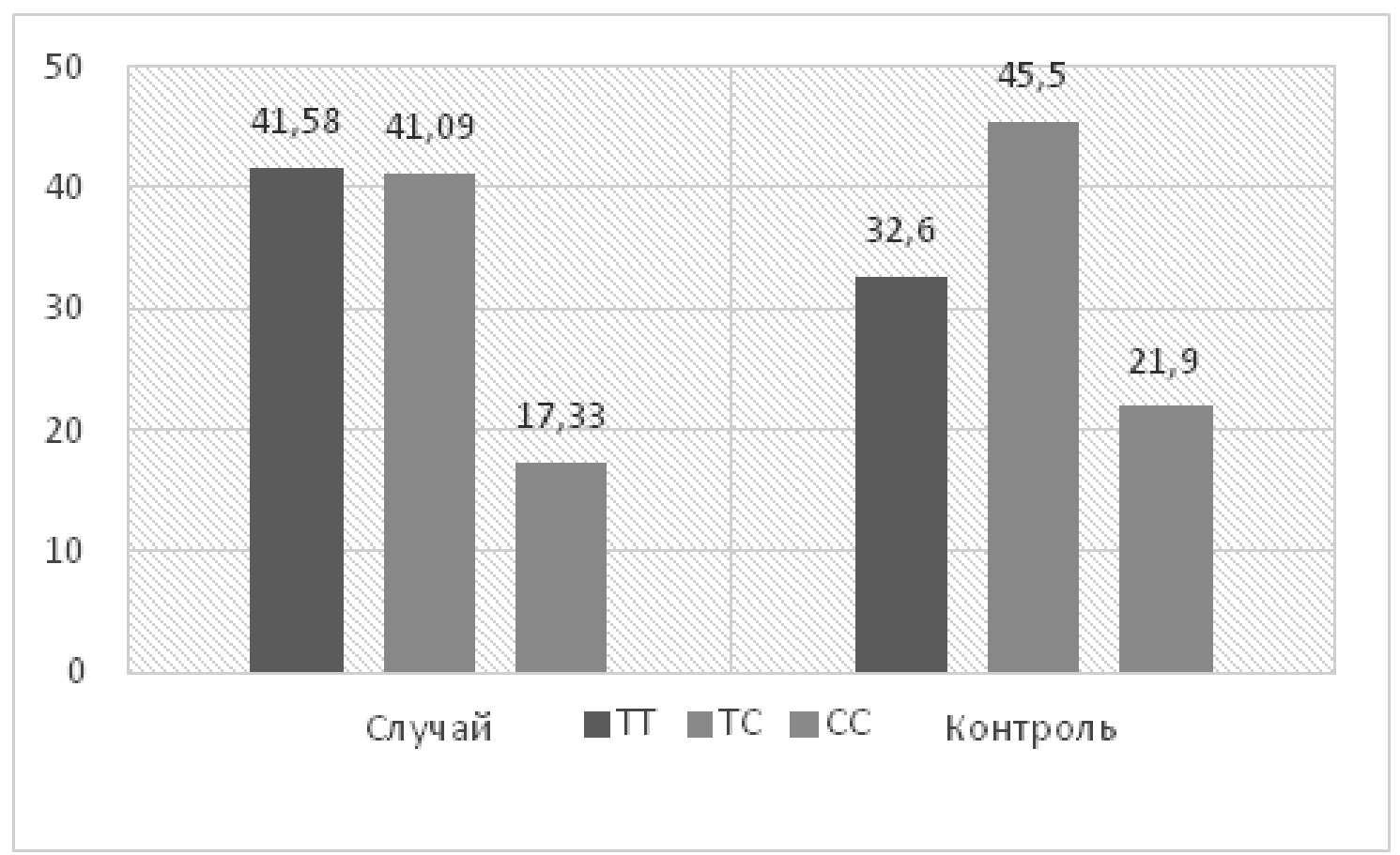

Рис. 2. Сравнительный анализ частоты генотипов полиморфизма Mspl гена CYP1A1 в двух исследованных выборках чеченцев: пациентов и контроля

Таблица 3.

Суммарное ОШ и 95\% ДИ ассоциаций между CYP1A1 Mspl полиморфизмом и риском рака молочной железы

\begin{tabular}{|c|c|c|c|c|c|c|}
\hline \multicolumn{2}{|c|}{ СС против ТТ } & \multicolumn{2}{c|}{ ТС против ТТ } & \multicolumn{2}{c|}{ СС против ТС+ТТ } & \multicolumn{2}{c|}{ СС+ТС против ТТ } \\
\hline $\begin{array}{c}\text { ОШ } \\
95 \% \text { ДИ }\end{array}$ & $P$ & $\begin{array}{c}\text { ОШ } \\
95 \% \text { ДИ }\end{array}$ & $P$ & $\begin{array}{c}\text { ОШ } \\
95 \% \text { ДИ }\end{array}$ & $P$ & $\begin{array}{c}\text { ОШ } \\
95 \% \text { ДИ }\end{array}$ \\
\hline $\begin{array}{c}0,64 \\
0,40-1,02\end{array}$ & 0,037 & $\begin{array}{c}0,71 \\
0,49-1,03\end{array}$ & 0,083 & $\begin{array}{c}0,77 \\
0,50-1,18\end{array}$ & 0,243 & $\begin{array}{c}1,09 \\
0,76-1,55\end{array}$ \\
\hline
\end{tabular}

Таблица 4.

Частота генотипов и аллелей полиморфного варианта A4889G гена CYP1A1.

\begin{tabular}{|c|c|c|c|c|}
\multirow{2}{*}{ Генотипы } & \multicolumn{2}{|c|}{ Случай, $\mathrm{n}=205$} & \multicolumn{2}{c|}{ Чонтроль, $\mathrm{n}=358$} \\
\cline { 2 - 5 } & \multicolumn{2}{|c|}{ Частота } & Абс. & \% \\
\cline { 2 - 5 } & A6c. & 94,15 & 331 & 92,46 \\
\hline AA & 193 & 5,37 & 27 & 0 \\
\hline AG & 11 & 0,49 & 0 & 96,2 \\
\hline GG & 1 & 96,8 & 689 & 3,77 \\
\hline A & 397 & 3,17 & 27 & 0 \\
\hline G & 13 & & 0,458 & \\
\hline
\end{tabular}

ным по аллелю дикого типа ТТ больше среди онкобольных: 41,58\% против 32,6\% в контрольной группе.

Для выявления ассоциаций между вариантами генотипов и риском развития злокачественной опухоли нами рассмотрены различные модели и определены для них значения ОШ с 95\% доверительным интервалом (табл.3). Как было отмечено выше, мы наблюдаем обратные корреляции, достоверные для рецессивной модели (ОШ = 0,64 при 95\% ДИ $0.40-1,02, p \leq 0,037)$. Во всех остальных случаях $\mathrm{p} \geq 0,05$.

Для другого полиморфизма гена CYP1A1(Ile462Val, rs1048943 характерна низкая частота встречаемости 
на изученной территории. Несмотря на то, что частота минорного аллеля G в обеих группах (пациентов и контрольной) практически одинакова: 3,17\% и 3,77\%, в популяционной выборке в гомозиготе данный аллель не обнаруживался, тогда как в выборке пациентов выявлен один случай с наличием гомозиготного генотипа GG. B группе пациентов частота гетерозиготных носителей данного аллеля составила 5,37\%, что на 2,14\% ниже в сравнении с популяционной выборкой (табл.4).

Мы сравнили результаты генотипирования в обеих группах, а также сравнили данные популяционной выборки с данными полученными в Курской области [1], признанной, согласно доклада «Состояние онкологической помощи населению России в 2018 году» Московского научно-исследовательского онкологического института имени Герцена, лидером по числу онкобольных (рис.3)

Сравнительный анализ показывает (рис. 4.), что в Курской области частота гетерозигот значительно выше, чем в исследованном районе: 14,2\% против 7,54 (p $\leq 0,05)$.
Более того, в Курской области есть случаи гомозиготного генотипа, тогда в ЧР гомозиготы практически не обнаруживаются, за исключением единичного случая в группе пациентов.

Генотипирование аллельных форм полиморфизма гена CYP1B1(Val432Leu) представлены в таблице 5.

В случае с полиморфизмом гена СYP1B1 мы наблюдаем, что в исследуемой группе высокая частота генотипа дикого типа: 60,6 в группу контроля и 57,7 в группе пациентов. Процент лиц с гомозиготным по минорному аллелю $\mathrm{G}$ генотипом составил в исследовании 2,23\% в контроле и 4,37 в выборке онкобольных.

Поиск корреляций между минорным аллелем G в гомозиготе и гетерозиготе обнаружил, что риск образования опухоли растет при условии наличия минорной аллели (табл. 6).

Однако полученные данные не достигают достоверно значимых результатов.

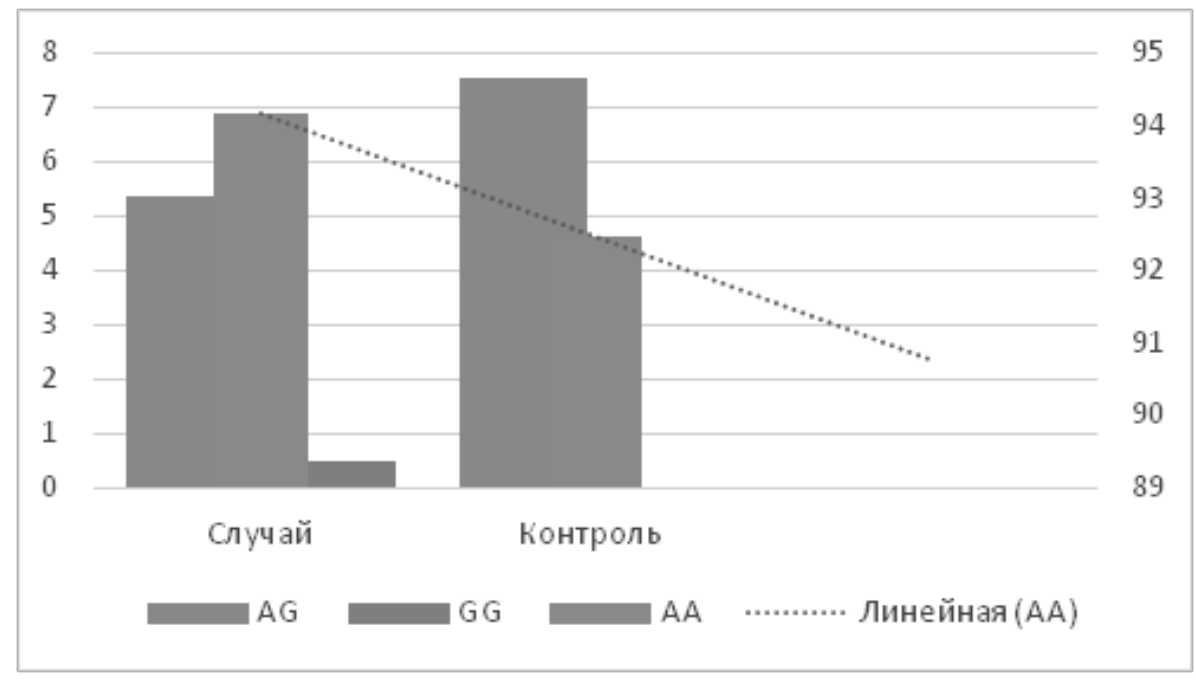

Рис. 3. Сравнительный анализ частоты генотипов полиморфного варианта A4889G гена CYP1A1

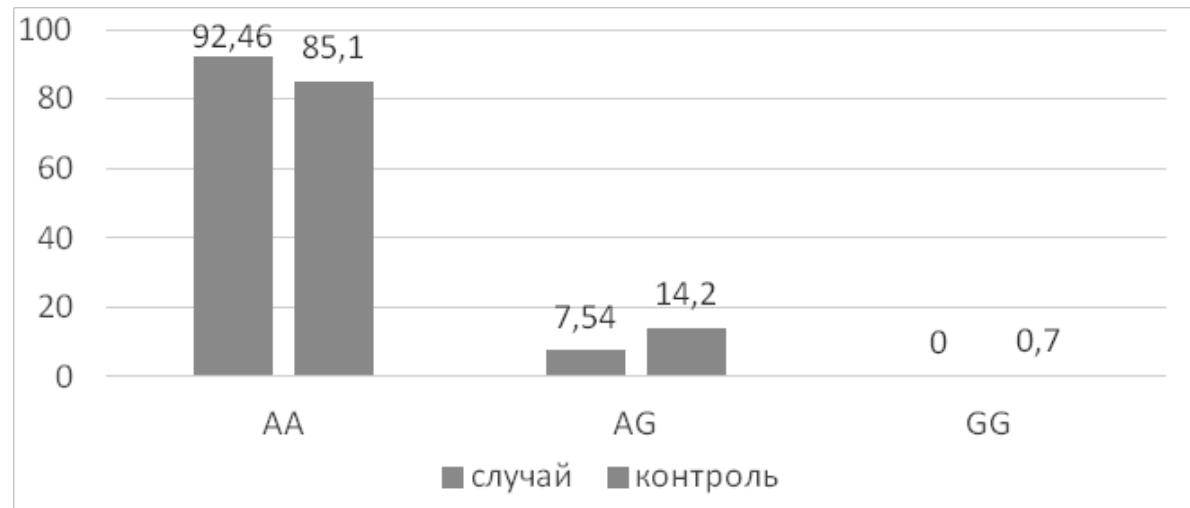

Рис. 4. Сравнительный анализ частоты генотипов полиморфного варианта A4889G гена CYP1A1 в ЧР и KO 
Таблица 5.

Частота генотипов и аллелей полиморфного варианта CYP1B1(Val432Leu) лиц изучаемых групп.

\begin{tabular}{|c|c|c|c|c|}
\hline \multirow{2}{*}{ Генотипы } & \multicolumn{2}{|c|}{ Случай, $\mathrm{n}=206$} & \multicolumn{2}{c|}{ Контроль, $\mathrm{n}=347$} \\
\cline { 2 - 5 } & $\mathrm{a} 6 \mathrm{c}$ & $\%$ & абс. & \multicolumn{2}{c|}{} \\
\hline CC & 119 & 57,7 & 217 & 32,5 \\
\hline CG & 78 & 37,9 & 122 & 2,3 \\
\hline GG & 9 & 4,37 & 8 & 82,6 \\
\hline C & 316 & 76,7 & 556 & 17,4 \\
\hline G & 96 & 23,3 & 138 & 0,054 \\
\hline
\end{tabular}

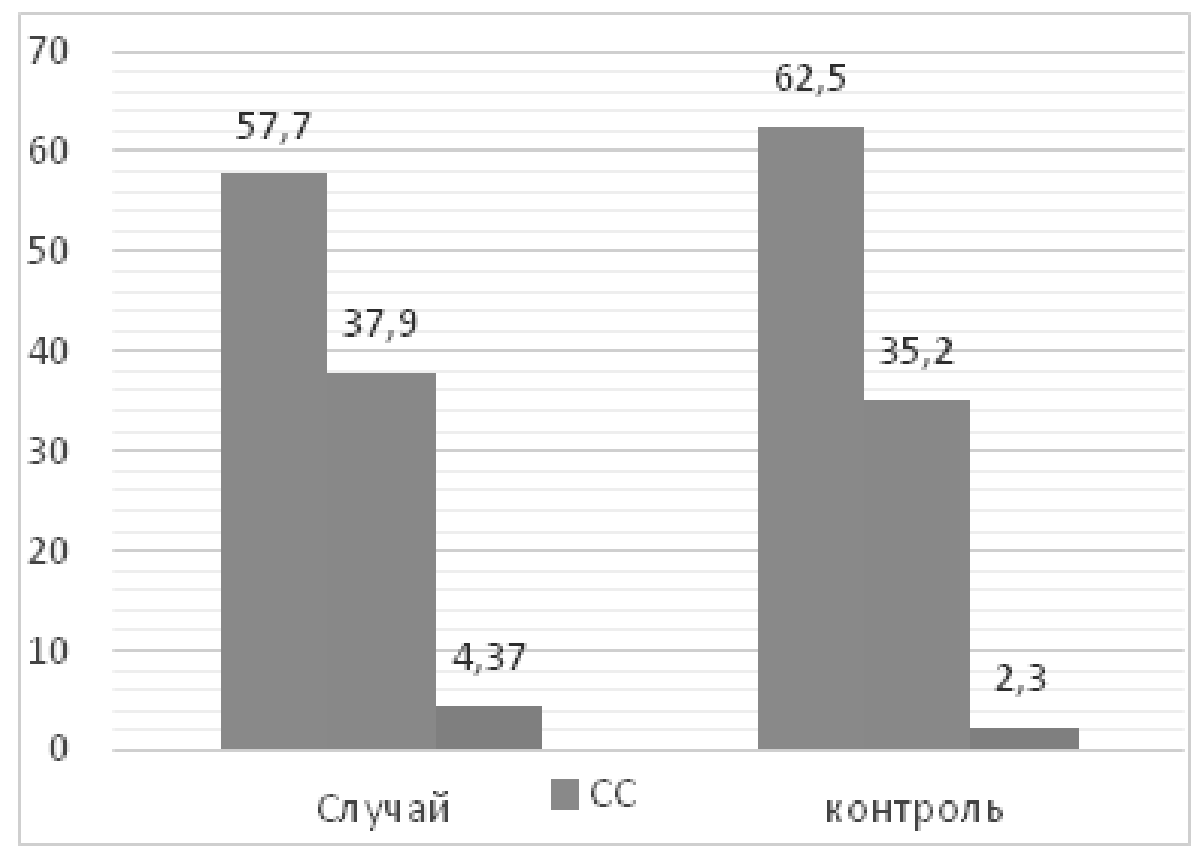

Рис. 5. Сравнительный анализ частоты генотипов полиморфного варианта гена CYP1B1(Val432Leu).

Таблица 6.

Суммарное ОШ и 95\% ДИ ассоциаций между CYP1B1(Val432Leu) полиморфизмом и риском рака молочной железы

\begin{tabular}{|c|c|c|c|c|c|c|c|}
\hline \multicolumn{2}{|c|}{ СС против ТT } & \multicolumn{2}{|c|}{ ТС против ТT } & \multicolumn{2}{|c|}{ СС против ТС+TТ } & \multicolumn{2}{|c|}{ СС+ТС против ТT } \\
\hline $\begin{array}{c}\text { оШ } \\
95 \% \text { дИ }\end{array}$ & $P$ & $\begin{array}{c}\text { ОШ } \\
95 \% \text { ДИ }\end{array}$ & $P$ & $\begin{array}{c}\text { ОШ } \\
95 \% \text { ДИ }\end{array}$ & $P$ & $\begin{array}{c}\text { ОШ } \\
95 \% \text { ДИ }\end{array}$ & $P$ \\
\hline $\begin{array}{c}2,05 \\
0,77-5,44\end{array}$ & 0,195 & $\begin{array}{c}1,17 \\
0,86-0,67\end{array}$ & 0,406 & $\begin{array}{c}1,94 \\
0,74-5,09\end{array}$ & 0,205 & $\begin{array}{c}1,22 \\
0,86-1,73\end{array}$ & 0,281 \\
\hline
\end{tabular}

\section{Зак^ючение}

На сегодняшний день установлено, что межэтнические различия генетически детерминированы [6]. Многочисленные исследования ученых отмечают уникальность генетической информации и его роль в этиологии наследственных заболеваний в разных этнических популяциях. Специфика распределения полиморфных вариантов генетических систем в популяциях может детерминировать этнические особенности в формировании фенотипов с предрасположенностью организма человека к заболеваниям. В большей степени это характерно для моногенных заболеваний, но тем не менее, в ряде исследований спорадических форм МФЗ показаны популяционные особенности генетической компоненты этих заболевания. Необходимость изучать особенности в развитии МФЗ заключается в том, что они являются основой для генетики патологий и молекулярной эпиде- 
миологии [2].

Выявление биогенетических маркёров повышенной этнической чувствительности особенно актуально для онкологических заболеваний, частота которых увеличивается с каждым годом. Различные однонуклеотидные полиморфизмы в генах могут объяснить различия между индивидуумами и их способность реагировать на факторы окружающей среды и отвечать в форме образования злокачественных опухолей. Это может быть одной из причин, объясняющей различный характер распространенности онкозаболеваний в отдельных регионах, наряду с социально-экономическими. По данным литературного обзора генетические полиморфизмы изоферментов СҮР450, могут иметь этиологическую роль при раковых заболеваниях молочной железы [9; 12].

Из всех ферментов цитохрома Р450 фермент CYP1B1 имеет самые высокие уровни активности гидроксилирования эстрогена и уровни экспрессии в ткани молочной железы [13]. Различные однонуклеотидные полиморфизмы в гене CYP1B1 могут объяснить различия между индивидуумами в ферментативной активности белка CYP1B1 и, следовательно, способность метаболизировать эстроген, который необходим для развития и регуляции женской репродуктивной системы $[11 ; 3]$.

В настоящем исследовании были проанализированы полиморфизмы генов CYP1A1 (A4889G и Mspl) и CYP1B1 (Val432Leu) в этнически однородной популяции, на- ходящейся в районе с высоким значением показателя онкозаболеваемости молочной железы. Результаты не выявили значимых различий частоты встречаемости генотипов по полиморфным вариантам генов СYP1A1 (A4889G) и CYP1B1 (Val432Leu) при сравнении с другими европейскими популяциями при общей тенденции увеличения доли минорных гомозигот на изученной территории.

Интересно, что минорный аллель G полиморфного варианта гена CYP1A1A4889G в гомозиготе выявился только в выборке пациентов. Кроме того, данный аллель является маркерным для Курской области, отличающейся самым высоким по России уровнем онкозаболеваемости. По данным статистики [5], уровень онкозаболеваний в Чеченской республике один из самых низких. Значимая разница в полученных результатах по однонуклеотидной замене в гене CYP1B1 (Val432Leu) в двух регионах, а также его выявление в чеченской популяции в гомозиготе в группе пациентов, на наш взгляд, подчеркивает необходимость дальнейшего исследования данного варианта в больших по объему выборках.

Таким образом, проведенные исследования не только вносят вклад в научно-теоретические знания, но и являются обоснованием для продолжения изучения уровня и спектра мутаций генов цитохромов в более масштабных исследованиях с применением новейших генетических технологий.

\section{ЛИТЕРАТУРА}

1. Москалев А.С. Исследование взаимосвязи полиморфизмов I462V гена СҮР1A1 и -9-154С >A гена СYР1A2 с риском развития колоректального рака у русских жителей Центральной России. / А.С. Москалев, В.О. Солдатов, И.Н. Вдовина, Н.В. Иванова, В.П. Иванов, А.В. Полоников, 0.Ю. Бушуева //Медицинская генетика. 2017;16(3):41-45.

2. Гервас П.А., Молоков А.Ю., Панферова Е.В., Писарева Л.Ф., Чердынцева Н.В. Этнические аспекты наследственного рака молочной железы Сибирский онкологический журнал. 2019; 18(2). -С.102-109

3. Захаров И.С. Роль полиморфизма гена СҮР1В1 в формировании постменопаузального остеопороза/ И.С. Захаров, В.Г. Мозес, Г.А. Ушакова, Г.И. Колпинский, Л.А. Гордеева, Е.В. Рудаева// Медицина в Кузбассе, №. 1, 2017, С. 57-60

4. Лещенко Я.А. Онкологическая заболеваемость населения промышленного города Иркутской области // Международный журнал прикладных и фундаментальных исследований. - 2014. - № 11-4. - С. 666-670

5. Состояние онкологической помощи населению России в 2018 году. /под ред. А.Д. Каприна, В.В. Старинского, Г.В. Петровой //М.: МНИОИ им. П.А. Герцена, филиал ФГБУ «НМИЦ радиологии», 2018

6. Супрун С.В., Кудряшова 0.С., Наговицына Е.Б., Лебедько О.А. Геномные особенности системы детоксикации у пришлого и коренного населения Приамурья // Бюллетень физиологии и патологии дыхания. 2018. №. 70. С. $42-48$.

7. Abramson JH. WINPEPI (PEPI-for-Windows): computer programs for epidemiologists. Epidemiol Perspect Innov. 2004;1(1):6. Published 2004 Dec 17. doi:10.1186/1742-5573-1-6

8. Fan-dong Meng. Association between cytochrome P450 1A1 (CYP1A1) gene polymorphisms and the risk of renal cell carcinoma: a meta-analysis/ Fan-dong Meng, Ping Ma, Cheng-guang Sui, Xin Tian,1 and You-hong Jianga//Meng Sci Rep. 2015; 5: 8108.doi: 10.1038/srep08108.

9. Ghisari et al., 2017 M. Ghisari, M. Long, D.M. Roge, J. Olsen, E.C. Bonefeld-JorgensenPolymorphism in xenobiotic and estrogen metabolizing genes, exposure to perfluorinated compounds and subsequent breast cancer risk: A nested case-control study in the danish national birth cohort Environ. Res., 154 (2017), pp. $325-333$

10. Hallmark B. Genomic Evidence of Local Adaptation to Climate and Diet in Indigenous Siberians/ B.Hallmark, T.M. Karafet, P. Hsieh, L.P Osipova, Watkins JC, Hammer 
MF//Mol Biol Evol. 2019 Feb 1;36(2):315-327. doi: 10.1093/molbev/msy211.

11. Hanna I.H. Cytochrome P450 1B1 (CYP1B1) pharmacogenetics: association of polymorphisms with functional differences in estrogen hydroxylation activity/ Hanna IH, Dawling S, Roodi N, Guengerich FP, Parl FF.//Cancer Res. 2000 Jul 1;60(13):3440-4

12. Khalili-Tanha G. Association of CYP1A1 M2 (A2455G) Polymorphism with Susceptibility to Breast Cancer in Mazandaran Province, Northern Iran: A Case-control Study/Khalili-Tanha G, Barzegar A, Nikbakhsh N, Ansari-Pirsaraei Z.//Int J Prev Med. 2019; 10:92

13. Matos A. Epistatic Interaction of CYP1A1 and COMT Polymorphisms in Cervical Cancer/Matos A, Castelão C, Pereira da Silva A, Alho I, Bicho M, Medeiros R, Bicho MC//0xid Med Cell Longev. 2016; 2016:2769804)

14. Tsuchiya Y. Cytochrome P450-mediated metabolism of estrogens and its regulation in human/Tsuchiya Y, Nakajima M, Yokoi T.//Cancer Lett. 2005 Sep 28; 227(2):115-24

\footnotetext{
( ) Бисултанова Зура Исановна (zura_sun@mail.ru), Джамбетова Петимат Махмудовна (petimat-lg@rambler.ru), Ацаева Марет Махмудовна (acaeva-mm@mail.ru), Джамбетова Лидия Махмудовна (I_dzham17@mail.ru).
}

Журнал «Современная наука: актуальные проблемы теории и практики»

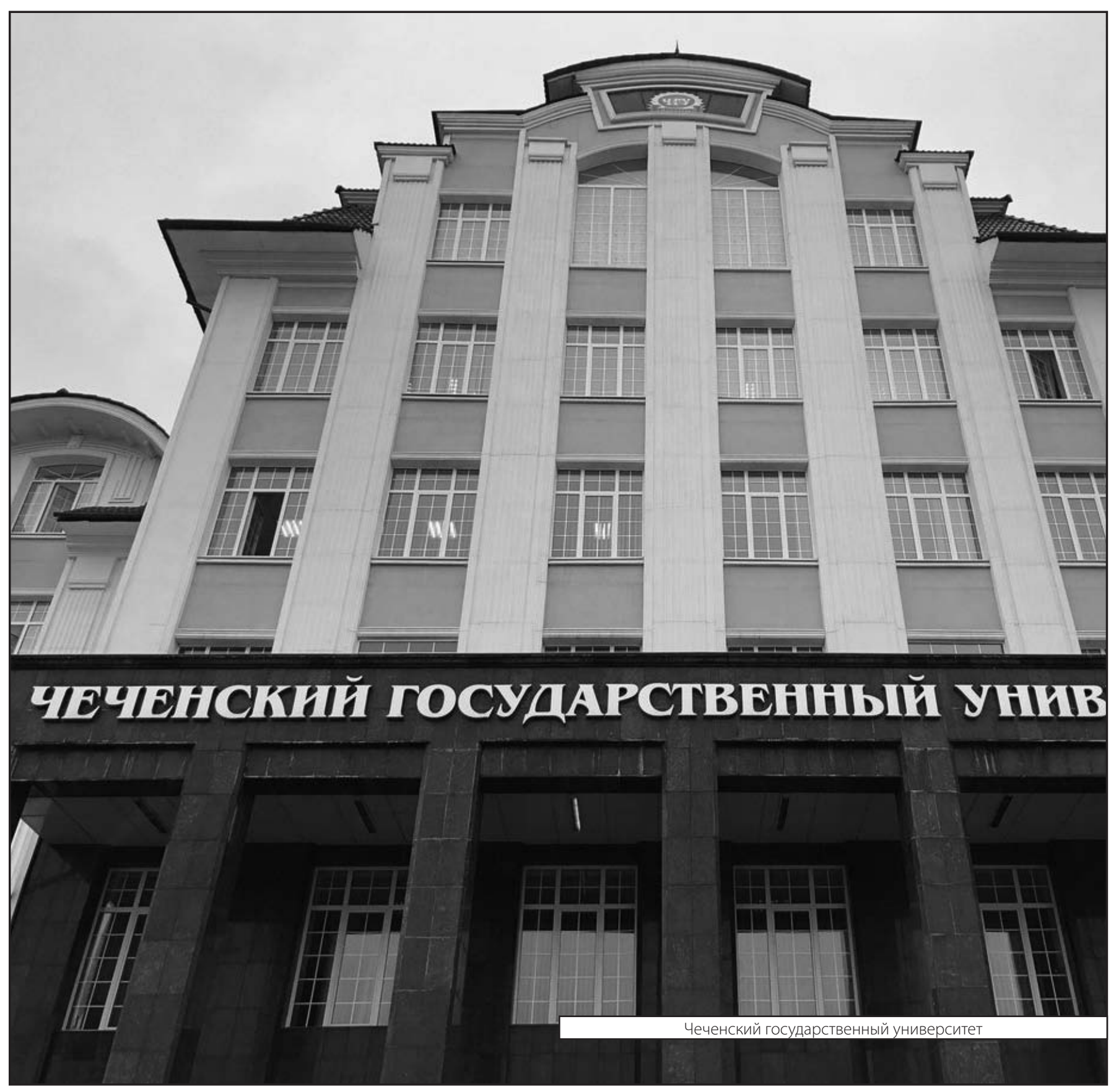

